\title{
RANCANG BANGUN WEBSITE E-COMMERCE PRODUK KERAJINAN BAMBU UNTUK PASAR EKSPOR
}

\author{
Ni Wayan Sumartini Saraswati ${ }^{1)}$ Ni Luh Pangestu Widya Sari ${ }^{2)}$ \\ Program Studi Teknik Informatika ${ }^{1) 2}$ \\ STMIK STIKOM Indonesia ${ }^{1)}$ 2) \\ sumartini.saraswati@gmail.com ${ }^{1)}$ pangestuwidyasari@gmail.com²)
}

\begin{abstract}
Indonesia is the third largest bamboo exporting country in the world which indicates that Indonesian bamboo products have the potential to be one of the export commodities. The technique of marketing bamboo handicraft products for the export market can use conventional methods such as participating in exhibitions abroad or entrusting products to relations that have overseas markets. The second, easier and cheaper way for small and medium-sized UKM is to use information technology and internet.In this study the design and development of e-commerce websites for handicraft products for the export market was carried out. This study aims to obtain minimum design specifications until the website can be used to market products online.The results of the design show that the website consists of two services in outline. The first is a page for consumers who shop, and the second is a page for admin to manage the website.The results of the design also show that the system can be built with only six tables in the database.
\end{abstract}

Keywords: export product marketing, e-commerce website, sales information system.

\begin{abstract}
ABSTRAK
Indonesia adalah negara pengekspor bambu terbesar ketiga di dunia yang mengindikasikan bahwa produk bambu Indonesia potensial untuk dijadikan salah satu komoditas ekspor. Teknik memasarkan produk kerajinan bambu untuk pasar ekspor dapat menggunakan metode konvensional seperti mengikuti pameran di luar negeri atau menitipkan produk pada relasi yang memiliki pasar di luar negeri. Cara yang kedua yang lebih mudah, murah dan terjangkau untuk UKM kecil dan menengah adalah dengan memanfaatkan teknologi informasi dan internet.Dalam Penelitian ini dilakukan perancangan dan pengembangan website e-commerce produk kerajinan untuk pasar ekspor. Penelitian ini bertujuan mendapatkan spesifikasi rancangan minimum hingga website dapat digunakan untuk memasarkan produk secara online. Hasil perncangan didapatkan bahwa website terdiri dari dua layanan secara garis besar. Yang pertama adalah halaman untuk konsumen yang berbelanja, dan yang kedua adalah halaman untuk admin dalam memanajemen website.
\end{abstract}

Kata Kunci: pemasaran produk ekspor, website e-commerce, sistem informasi penjualan.

\section{PENDAHULUAN}

Indonesia menjadi salah satu negara pengekspor produk bambu terbesar dunia. Tercatat Indonesia menempati peringkat tiga dunia. Sebagai negara pengekspor produk bambu dengan pangsa pasar 7 persen dan nilai ekspor terbesar USD 490 atau sekitar Rp 6 Triliun. Produk bambu dari Indonesia ini merupakan produk setengah jadi dan produk jadi. Contoh untuk produk jadi yang diekspor seperti aneka kerajinan, furniture, dan beragam jenis alat musik.

Teknik memasarkan produk kerajinan bambu untuk pasar ekspor dapat menggunakan metode konvensional seperti mengikuti pameran di luar negeri atau menitipkan produk pada relasi yang memiliki pasar di luar negeri. Cara yang kedua yang lebih mudah, murah dan terjangkau untuk UKM adalah dengan memanfaatkan teknologi informasi dan 
internet.

Mempunyai website adalah langkah pertama yang perlu dikerjakan untuk menembus pasar ekspor lewat internet. Melewati website inilah calon konsumen memperoleh info selengkapnya tentang penjual, barang apa yang di produksi, berapakah besar kemampuan produksi, bagaimana mutu barang, dan info pendukung yang lainnya. Website dapat melengkapi atau menjadi substitusi catalog product yang umumnya diciptakan oleh beberapa eksportir serta disebarluaskan ke calon buyer di beberapa Negara. Bedanya, di website dapat memperbarui beberapa produk dengan mudah serta cepat hingga calon buyer senantiasa memperoleh info terbaru.

Departemen Peridustrian dan Perdagangan Kabupaten Bangli membina banyak UKM yang tidak mampu memperluas pemasaran dengan cara mengikuti pameran di luar negeri mengingat modal yang terbatas. Padahal hasil kerajinannya berkualitas dan mampu bersaing di pasar global, seperti produk kerajinan yang dihasilkan UKM Ade Prima Bambu. UKM tersebut menghasilkan kerajinan bambu bakar yang sangat indah seperti ditunjukkan oleh gambar 1

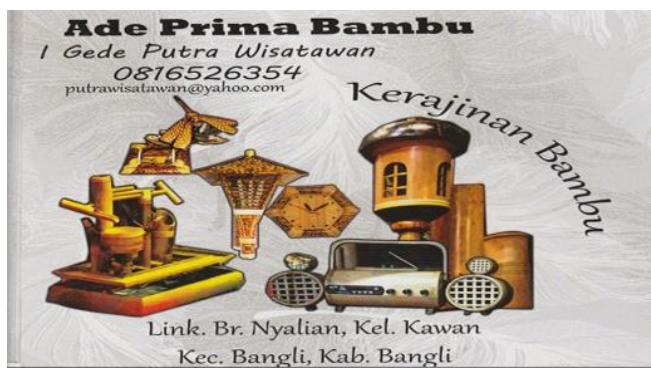

Gambar 1 Kerajinan Bambu Bakar

Melalui Penelitian ini diharapkan dihasilkan website yang mampu menjadi wadah bagi pengerajin bambu di wilayah kabupaten Bangli untuk memasarkan produknya secara luas dengan dukungan teknologi internet. Dengan demikian diharapkan angka ekspor produk kerajinan akan meningkat yang artinya juga memberikan masukan devisa bagi negara.

Dari pemaparan mengenai permasalahan di atas maka dalam penelitian ini ingin dirancang dan dikembangkan website produk kerajinan bambu untuk pasar ekspor dimana mengambil studi kasus pengerajin bambu di kabupaten Bangli.

Penelitian ini bertujuan untuk menghasilkan rancangan dan produk website untuk kerajinan bambu dengan pangsa pasar ekspor.

Adapun manfaat penelitian ini adalah :

1. Untuk mendapatkan spesifikasi minimum rancangan baik database maupun bisnis proses e-commerce agar dapat digunakan dalam acuan untuk proses penelitian sejenis maupun rujukan bahan ajar di bidang teknik informatika.

2. Untuk mendapatkan aplikasi website ecommerce yang dapat digunakan untuk memperluas jangkauan pemasaran pengerajin.

\section{TINJAUAN PUSTAKA}

\section{Sistem Informasi}

McLeod (2001) mendefinisikan sistem sebagai sekelompok elemen yang terintegrasi dengan maksud yang sama untuk mencapai suatu tujuan. Suatu organisasi seperti perusahaan atau suatu bidang fungsional sangat cocok dengan definisi ini.

Menurut pendapat O’Brien (2003), sistem informasi adalah suatu kombinasi yang terorganisasi dari sumber daya manusia, perangkat keras, perangkat lunak, jaringan komunikasi, dan sumber data yang mengumpulkan, mengubah, dan menyebarkan informasi ke dalam sebuah organisasi. Sistem Informasi tidak terlepas dari data dan informasi.

Data terdiri dari fakta-fakta dan angkaangka yang relatif tidak berarti bagi pemakai. Saat data ini diproses, data tersebut dapat diubah menjadi informasi. Sedangkan pengertian informasi adalah data yang telah diproses, atau data yang memiliki arti. Informasi juga bisa diartikan sebagai data yang diolah menjadi bentuk yang lebih berguna dan lebih berarti bagi yang menerimanya. Informasi sangat dibutuhkan karena informasi merupakan suatu dasar dalam mengambil keputusan dalam perusahaan. Pengolah informasi adalah salah satu elemen kunci dalam sistem konseptual. Pengolah informasi dapat meliputi elemenelemen komputer, elemen-elemen nonkomputer, atau kombinasi keduanya (McLeod, 2001). 


\section{E- Commerce}

Menurut Purbo dan Wahyudi $(2001,2)$ E-Commerce merupakan satu set dinamis teknologi, aplikasi, dan proses bisnis yang menghubungkan perusahaan, konsumen, komunitas tertentu melalui transaksi elektronik dan perdagangan barang, pelayanan, dan informasi yang dilakukan secara elektronik.

Menurut Nugroho (2006, 1) Electronik Commerce (E-Commerce) merupakan konsep baru yang biasa digambarkan sebagai proses jual beli barang atau jasa pada world wide web internet atau proses jual beli atau pertukaran produk, jasa dan informasi melalui jaringan informasi termasuk internet. E-Commerce merupakan kegiatan bisnis yang dijalankan secara elektronik melalui suatu jaringan internet atau kegiatan jual beli barang atau jasa melalui jalur komunikasi digital.

\section{Jenis E-Commerce}

Menurut Quthni (2006, 2). Dalam terminology E-Commerce yang popular, transaksi yang dilakukan didasarkan pada beberapa jenis yaitu sebagai berikut:

1. B2B (Bussiness to Bussiness) yaitu situs web E-Commerce yang melakukan kegiatan bisnis antar pelaku kegiatan bisnis, adapun karakteristik dari jenis B2B (Bussiness to Bussiness) yaitu:

a. Pertukaran data (data exchange) berlangsung berulang-ulang dan secara berkala, misal setiap hari, dengan format yang sudah disepakati bersama. Dengan kata lain, servis yang digunakan sudah tertentu. Hal ini memudahkan pertukaran data untuk dua entity yang menggunakan standar yang sama.

b. Salah satu pelaku dapat melakukan inisiatif untuk mengirimkan data, tidak harus menunggu partnernya.
2. B2C (Bussiness to Customer) yaitu situs web E-Commerce yang melakukan kegiatan bisnis langsung dengan konsumen. Karakteristik B2C (Bussiness to Customer) yaitu:

a. Terbuka untuk umum, dimana informasi disebarkan ke umum.

b. Servis yang diberikan bersifat umum (generic) dengan mekanisme yang dapat digunakan oleh khalayak ramai.

c. Servis diberikan berdasarkan permohonan (on demand). Konsumen melakukan inisiatif dan produser harus siap memberikan respon sesui dengan permohonan.

3. B2G (Bussiness to Goverment) yaitu situs web E-Commerce yang melakukan kegiatan bisnis dengan pemerintah.

4. $\mathrm{C} 2 \mathrm{~B}$ (Consumen to Bussiness) dalam $\quad \mathrm{C} 2 \mathrm{~B}$ konsumen memberitahukan kebutuhan atas suatu produk atau jasa tertentu, dan para pemasok bersaing untuk menyediakan produk atau jasa tersebut ke konsumen, contohya di priceline.com, dimana pelanggan menyebutkan produk dan harga yang diinginkan.

5. C2C (Customer to Customer) yaitu situs web E-Commerce yang melakukan kegiatan bisnis antar konsumen. Contoh $\mathrm{C} 2 \mathrm{C}$ adalah iklan baris dan toko-toko buku online yang dimiliki oleh individu yang pada umumnya memanfaatkan layanan blog gratis seperti blogspot.

6. Mobile Commerce (M-Commerce) yaitu transaksi dan aktivitas EC dilakukan dengan teknologi wireless (misal telepon selular).

7. E-Learning yaitu penyampaian informasi secara online untuk tujuan pelatihan dan pendidikan. 
8. Exchange (E-Exchange) yaitu pasar elektronik untuk umum yang beranggotakan banyak pembeli dan penjual dentamedia Online termasuk kedalam jenis situs $\mathrm{C} 2 \mathrm{C}$ atau Customer to Customer.

\section{Website}

Menurut Suyanto $(2006,34)$ website adalah keseluruhan halaman-halaman web yang terdapat dalam sebuah domain yang mengandung informasi. Sebuah website biasanya dibangun atas banyak halaman web yang saling berhubungan. Jadi dapat dikatakan bahwa, pengertian website adalah kumpulan halaman-halaman yang digunakan untuk menampilkan informasi teks, gambar diam atau gerak, animasi, suara, dan atau gabungan dari semuanya, baik yang bersifat statis maupun dinamis yang membentuk satu rangkaian bangunan yang saling terkait, yang masing-masing dihubungkan dengan jaringan-jaringan halaman. Hubungan antara satu halaman website dengan halaman website lainnya disebut dengan hyperlink, sedangkan teks yang dijadikan media penghubung disebut hypertext.

\section{METODOLOGI PENELITIAN}

\section{Alur Penelitian}

Penelitian ini dikembangkan berdasarkan metodologi rekayasa dengan tahapan penelitian seperti ditunjukkan oleh gambar 2.

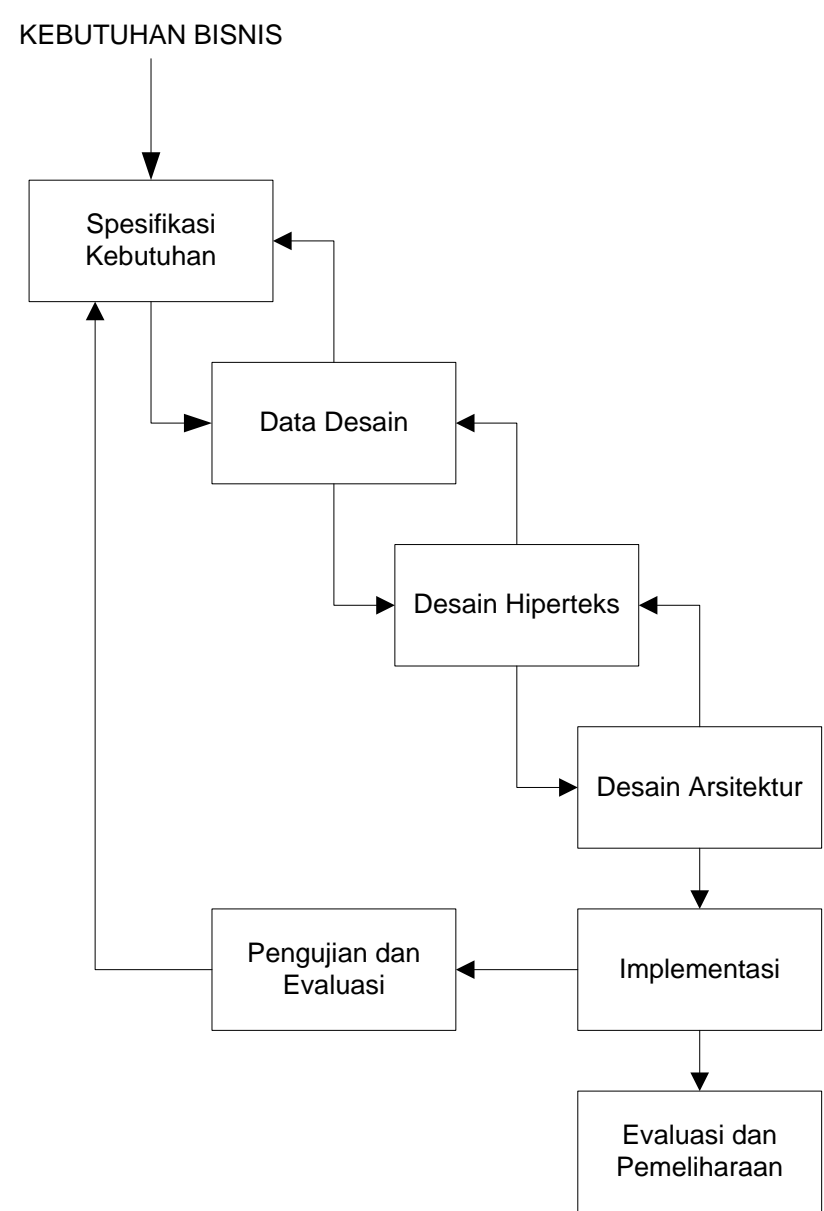

Gambar 2. Tahapan Penelitian

\section{Analisa Kebutuhan Sistem}

Analisa kebutuhan sistem yang digunakan adalah kebutuhan sistem fungsional dan terdapat dua alur yaitu alur dari halaman admin dan alur dari halaman publik.

\section{Halaman Admin}

Sistem yang dapat dilakukan pada alur halaman admin adalah sebagai berikut:

a. Sistem terdiri dari halaman login, yaitu halaman login admin

b. Admin dapat mengakses halaman admin dengan memasukkan username dan password admin terlebih dahulu. 
c. Admin yang login menggunakan username dan password yang tidak valid maka sistem tidak akan bisa mengakses halaman admin.

d. Halaman admin menyediakan manajemen pengelolaan data master serta manajemen order dan transaksi

\section{Halaman Publik}

Sistem yang dapat dilakukan pada halaman publik adalah sebagai berikut:

a. Halaman website publik merupakan halaman publik yang dapat diakses oleh pengunjung website yang ingin melihat dan membeli produk Akah Bali dan Ade Prima Bambu.

b. Pertama kali mengakses halaman publik, pengunjung dapat mengakses bagian halaman utama website dan bagian daftar produk untuk melihat produk apa saja yang dijual.

c. Untuk melakukan pembelian produk, pengunjung disediakan tombol add to chart untuk menambah ke dalam keranjang belanja pada bagian daftar produk yang diinginkan. Pengunjung juga dapat menentukan jumlah kuantitas produk yang akan dibeli.

d. Pada halaman keranjang belanja pengunjung dapat menghapus ataupun mengubah quantity produk yang sudah dipilih.

e. Proses pembelian dikatakan sah jika pengunjung sudah melakukan transfer dengan jumlah yang ditentukan dan memberikan konfirmasi transaksi serta pembayaran telah diverifikasi oleh Admin.

\section{Metode Analisis}

Dalam perancangan ini digunakan beberapa diagram untuk memodelkan spesifikasi fungsi-fungsi yang disediakan oleh sistem kepada user. Dengan menggunakan diagram, perancangan website dapat diwujudkan dalam bentuk simbol dan diagram. Perancangan dalam bentuk simbol dan diagram kemudian dapat diterjemahkan menjadi kode program pada website. Diagram tersebut antara lain:

\section{Data Flow Diagram (DFD)}

Data Flow Diagram ini merupakan alat perancangan sistem yang berorientasi pada alur data dengan konsep dekomposisi yang dapat digunakan untuk menggambarkan analisa maupun rancangan sistem yang mudah dikomunikasikan oleh profesional sistem kepada pemakai maupun pembuat program. 


\section{Diagram Konteks}

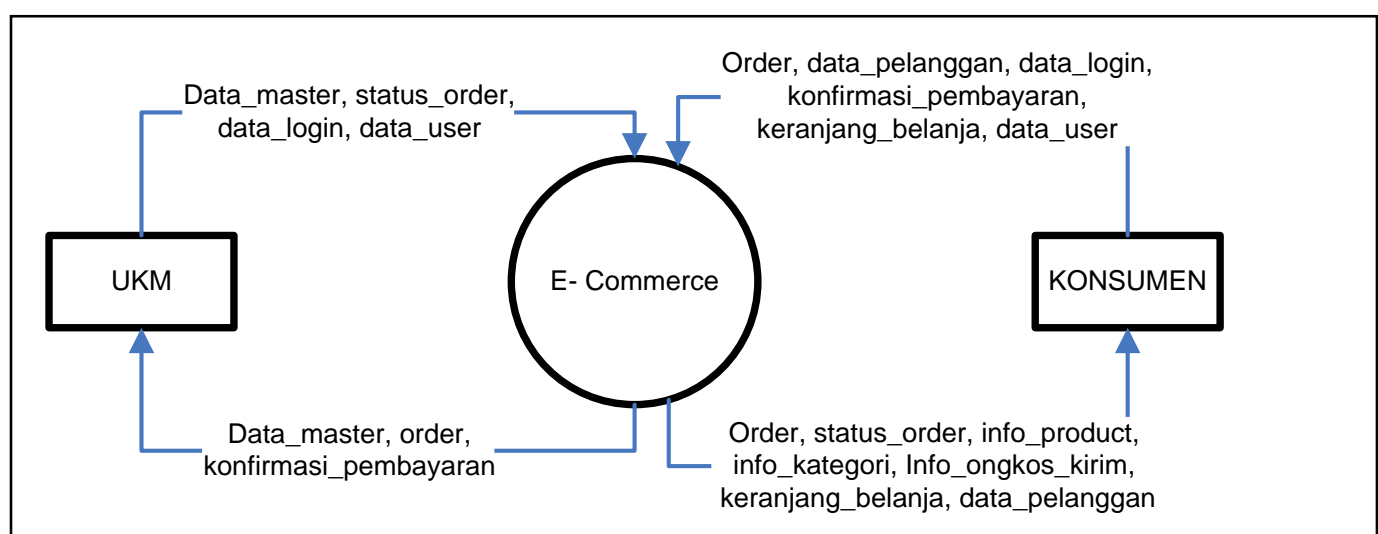

\section{Gambar 3 Konteks Diagram}

Diagram konteks pada gambar 3 menunjukan rancangan website e-commerce secara lengkap mengenai apa yang dilakukan konsumen dan UKM pada website e-commerce. UKM dapat melakukan pengelolaan website e-commerce kemudian dapat mengecek data master, dan dapat melakukan konfirmasi data pemesanan. Selanjutnya dari website sendiri memberikan informasi mengenai data master, data pemesanan, serta konfirmasi pembayaran. Untuk pengunjung melakukan input data pengunjung, data keranjang belanja, data pemesanan, dan konfirmasi transaksi selanjutnya website dapat memberikan informasi data pengunjung, data barang, data pemesanan, data keranjang belanja, dan data transaksi pemesanan. 


\section{DFD Level 0}

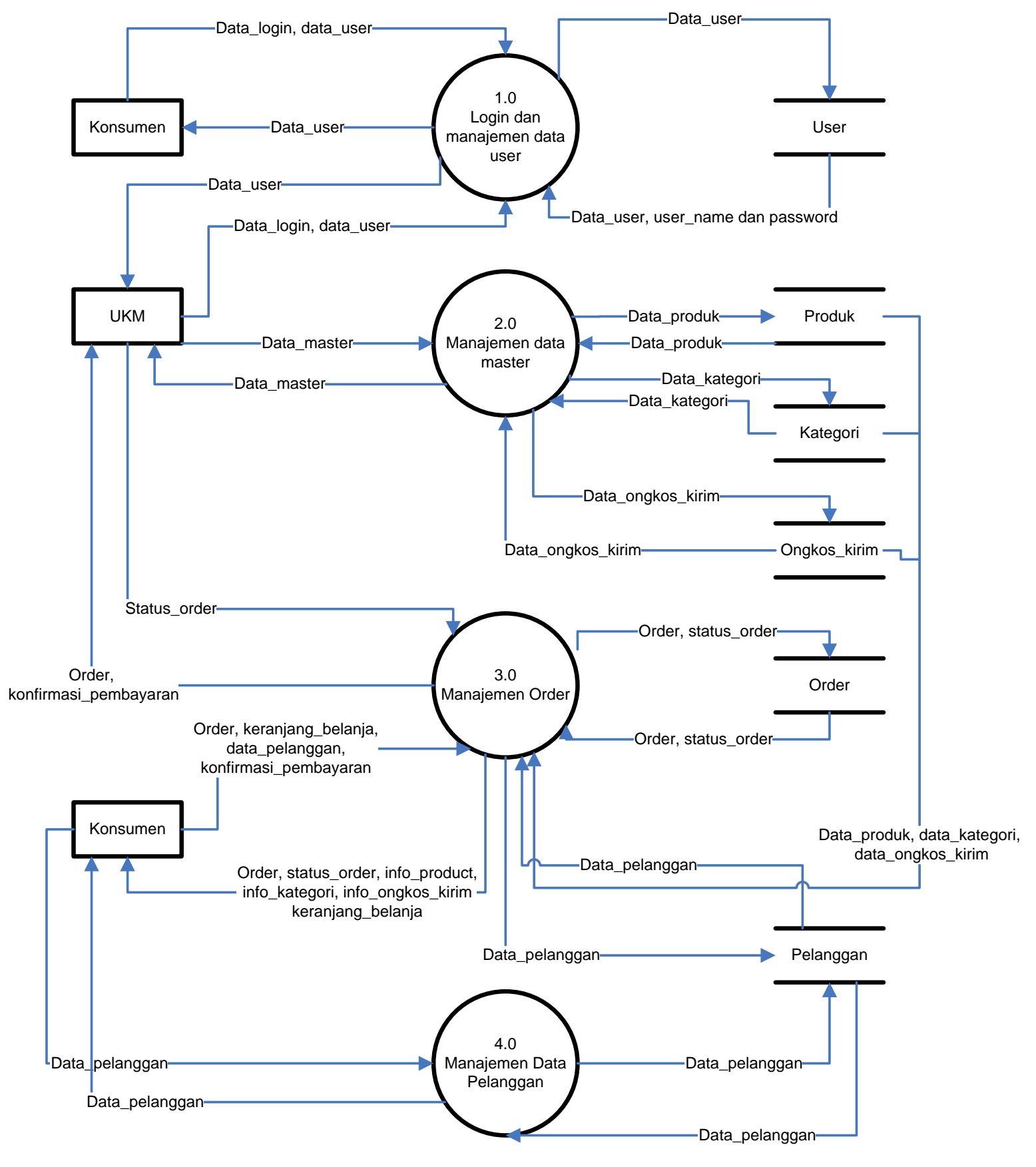

Gambar 4 Data Flow Diagram Level 0.

Data flow diagram level 0 pada gambar 4 diatas merupakan pengembangan dari diagram konteks. Dari diagram konteks dibuatkan data flow diagram level 0 untuk menggambarkan arus data yang lebih jelas dan detail yang terjadi didalam racangan website e-commerce. 


\section{Rancangan Basis Data}

Basis Data disusun menggunakan perancangan basis data relasional.
Gambar 5 menunjukkan diagram relasional database sistem

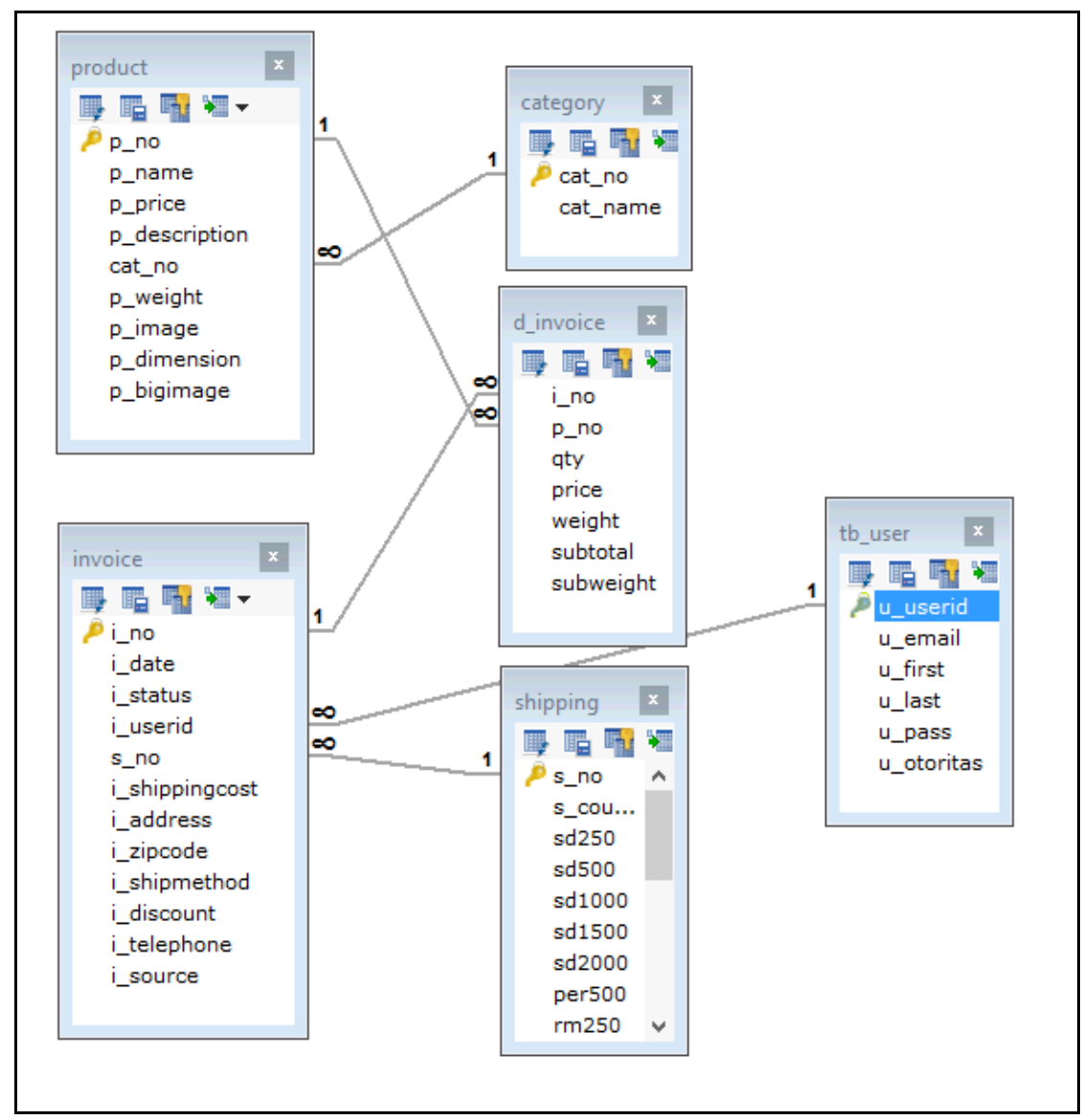

Gambar 5 Diagram Relational Database

Database aplikasi memiliki enam tabel sebagai berikut :

- Tabel Product yang berisi record product kerajinan

- Tabel Category yang berisi record kategori kerajinan

- Tabel Shipping yang berisi record data ongkos kirim untuk tiap negara

- Tabel Invoice yang berisi record order dari konsumen

- Tabel d_invoice yang berisi detail product dari tiap order konsumen

- Tabel tb_user yang berisi record user aplikasi baik konsumen maupun admin

\section{HASIL DAN PEMBAHASAN}

Sistem dibangun dengan bahasa pemrograman PHP dan database MySQL. Secara garis besar aplikasi dibangun dari dua sisi pengguna yaitu konsumen untuk berbelanja dan admin untuk manajemen data. Berikut adalah hasil pengembangan sistem yang diwakili oleh tampilan antar muka sistem :

\section{Tampilan dari sisi konsumen \\ Halaman home.}

Halaman ini adalah halaman pertama yang akan muncul saat alamat website diketikkan dalam browser. Pada halaman ini user dapat mengakses macam-macam produk yang dijual melalui menu pada bagian atas dan juga terdapat daftar produk best seller. 


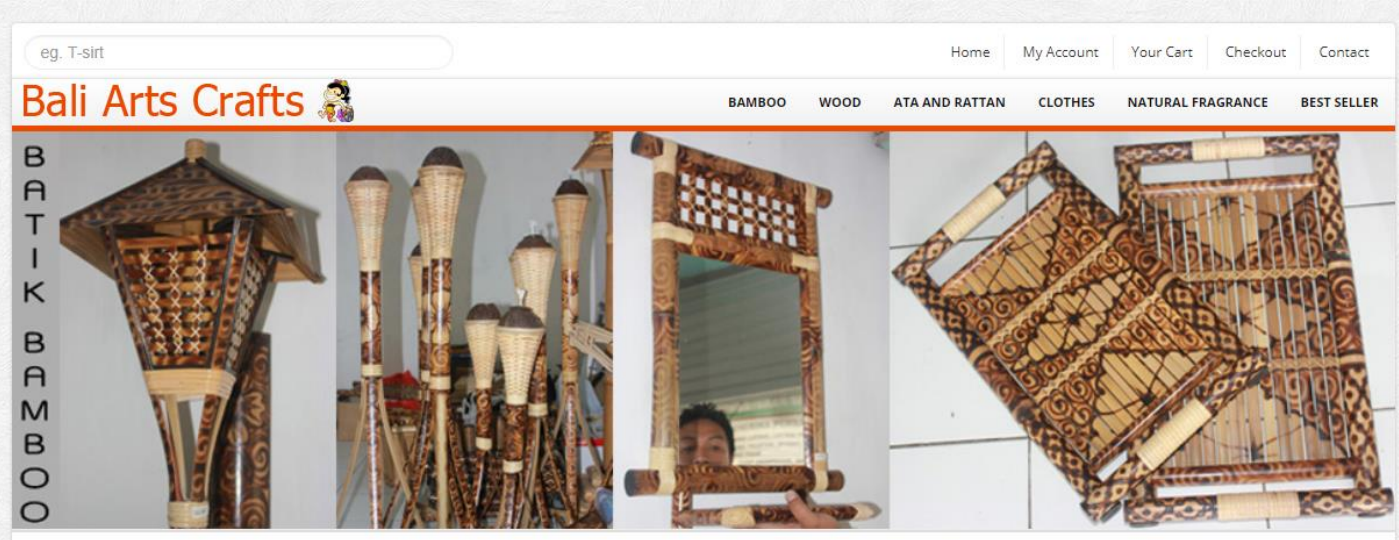

We are craftsmen from Bangli district, Bali Province, who make handicrafts made from bamboo. Bamboo is processed into high-quality crafts and has high artistic value since Bali is famous for culture and art. We can provide crafts for you based on large orders or small purchases.

Your purchase will help improve the welfare of the local community in the Bangli area.

BEST SELLER PRODUCTS

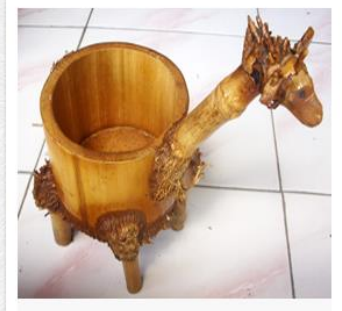

UNICORN BOTTLE CASE HEIGHT: 25 CM: WIDTH: $10 \mathrm{CM}$.

$\$ 3.3$

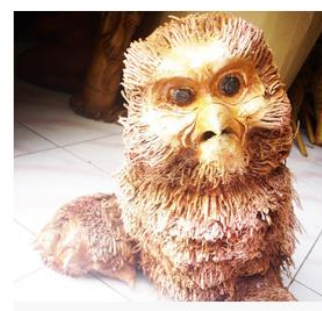

OWL SCULPTURE HEIGHT: 25 CM: WIDTH: 10 OM

$\$ 13$

\section{Navigation}

Homepage
About Us

About Us
Contac Us

Contac Us

Your Cast

$\log$

\section{My Account \\ Ball Arts Crafts s: \\ My Account \\ Order History
Wish List \\ Newsletrer \\ ewsletter}

Gambar 6 Halaman Home

\section{Halaman detail produk}

Halaman ini berisi informasi detail dari produk, misalkan deskripsi produk, ukuran dimensi produk, gambar produk yang lebih besar dan lain-lain. Pada halaman ini user dapat menekan tombol add to cart yang berfungsi untuk menambahkan produk ke dalam keranjang belanja. 


\section{Bali Arts Crafts}

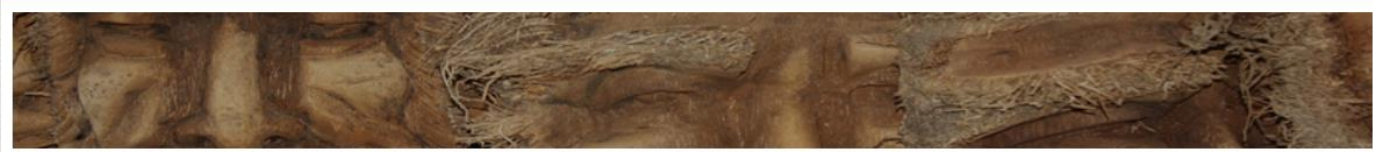

PRODUCT DETAIL

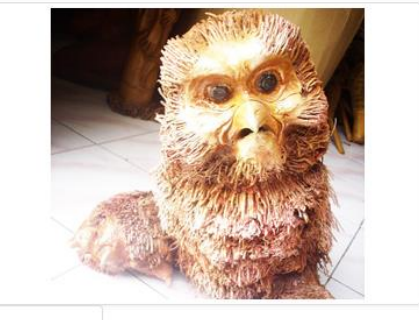

Description Additional Information
Product Name: Owil Sculprure

Product Category: Bamboo Root

Price: $\$ 13$

Qty: 12

Add to cart

Gambar 7 Halaman Detail Produk

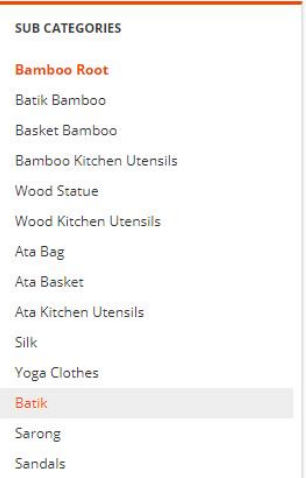

\section{Halaman keranjang belanja}

Halaman ini berisi daftar produk yang dipilih untuk dibeli oleh user. Daftar tersebut juga berisi kuantiti dari barang. Terdapat tiga tombol dalam halaman ini yaitu tombol update, continue, check out. Tombol update berfungsi untuk merubah kuantiti maupun jumlah item produk yang akan dibeli. Tombol continue dipilih jika user ingin melanjutkan pemilihan produk yang akan ditambahkan ke shopping cart. Tombol ini mengarahkan user ke halaman produk. Tombol check out digunakan untuk mengakhiri proses pembelanjaan dan user akan mengisi detail informasi pengiriman. Teknik pemrograman dalam shopping cart ini memanfaatkan variabelsession. 


\begin{tabular}{|c|c|c|c|c|c|c|c|}
\hline eg. T-sirt & & & Home & My Account & Your Cart & Checkout & Contact \\
\hline Bali Arts Crafts \$ै & BAMBOO & WOod & ATA AND RATTAN & CLOTHES & NATURAL F & GRANCE & BEST SELLER \\
\hline
\end{tabular}

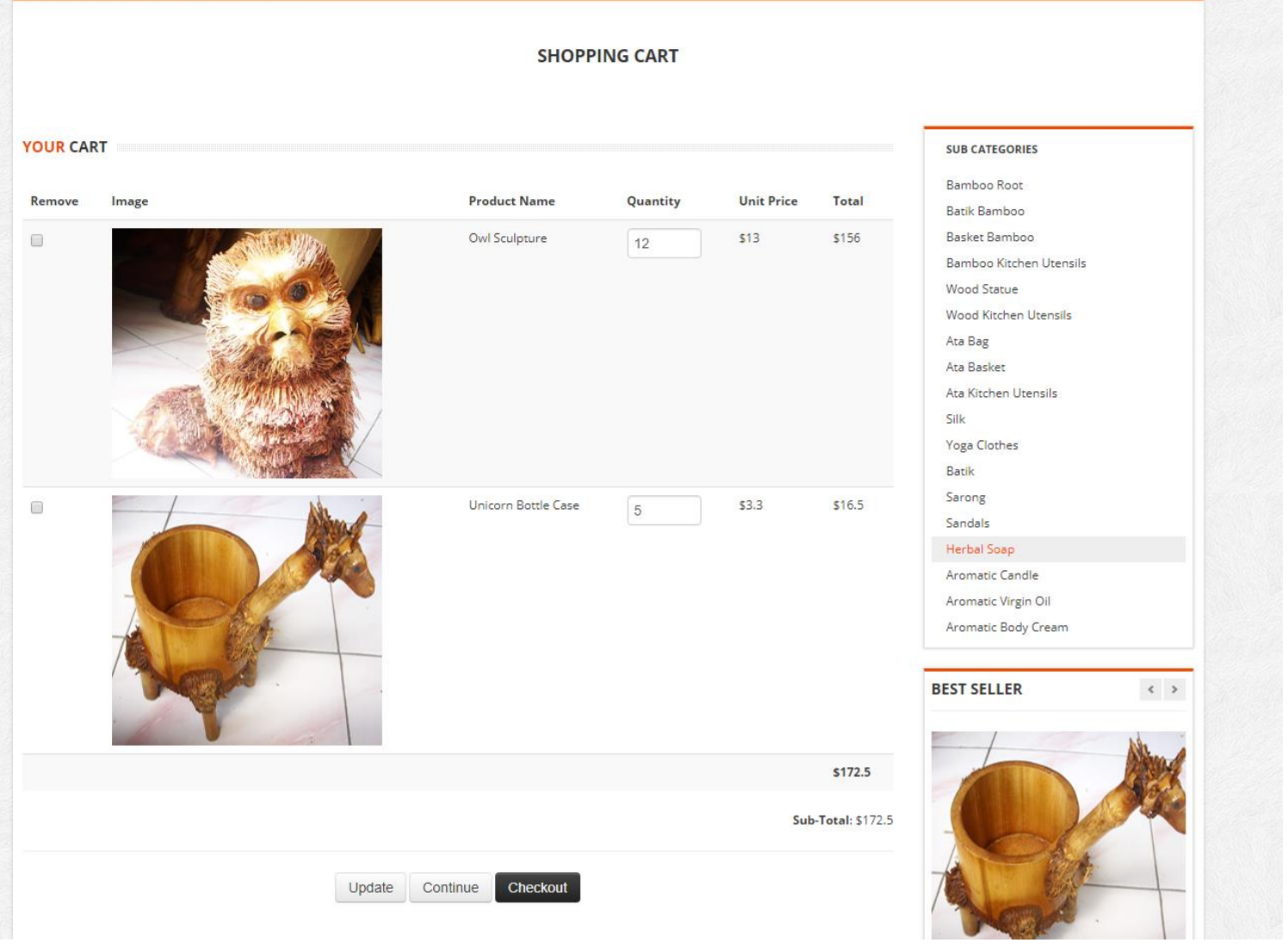

Gambar 8 Halaman Shopping Cart

\section{Halaman check out 1}

Pada halaman ini proses check out diawali dengan mendata user yang berbelanja. Pilihan aksi dibagi menjadi dua aktifitas yaitu untuk user baru memilih form registrasi user. Untuk konsumen lama yang telah pernah berbelanja sebelumnya cukup mengisi form login. Untuk form register data pelanggan akan diinput ke tabel user, sedangkan untuk form login akan mengecek apakah user yang login terdaftar dalam tabel user. 

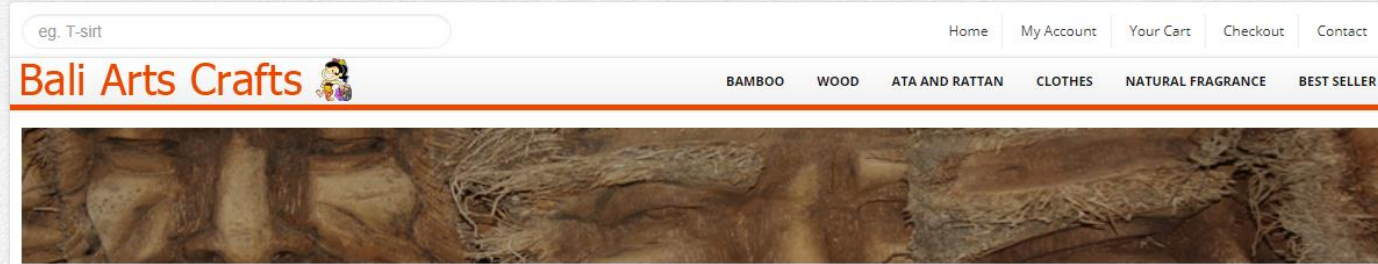

CHECK OUT

\section{Checkout Options}

New Customer

By creating an account you will be able to shop faster, be up to date on an order's status, and keep

track of the orders you have previously made.

First Name

Last Name

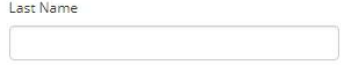

Email Address

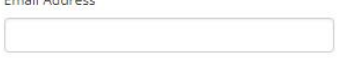

Password

Enter your password

Confirm Password

Enter your password

Gambar 9 Halaman Checkout 1

\section{Halaman check out 2}

Pada halaman ini user mengisi informasi tentang pengiriman yang berupa alamat dan metode pengiriman.

Dengan menekan tombol continue
Returning Customer

Username (Email)

geck_nik@yahoo.co.id

Password

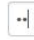

Forget Password

Continue

maka proses pemesanan selesai dan data invoice disimpan kedalam tabel invoice serta di email kan ke email konsumen 


\section{Bali Arts Crafts}

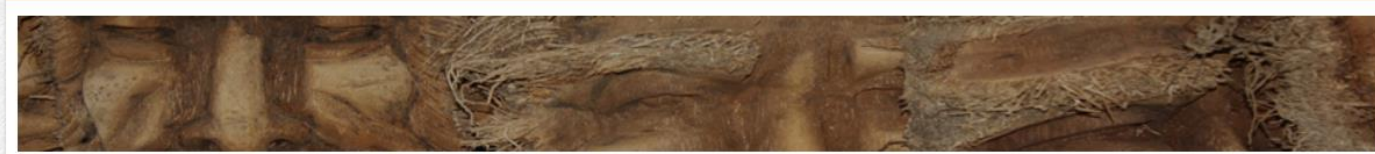

CHECK OUT

\section{Checkout Proccess}

Shipping Information

Full Name

Sumartini Saraswati

Email Adress

geck_nik@yahoo.co.id

Shipping Adress

II. Rava Tebongkang No 77 X Singakerta Ubud

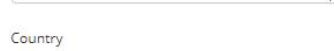

Zip Code

80571

Telephone

081339573357

Shipping Method

EMS (about 4-10 days)

- Registered Mail (about 14-30 days)

DHL (about $4-10$ days)

Terms and Condition

$\square$ By click this box you are agree with all terms and conditions.

Continue

Gambar 10 Halaman Checkout 2

\section{Tampilan dari sisi admin}

Antar muka admin digunakan untuk manajemen data produk, manajemen invoice, manajemen shipping cost, manajemen kategori dan manajemen user admin. Dalam jurnal ini hanya ditampilkan dua form yang paling penting dalam manajemen website.

\section{Halaman list invoice}

Pada halaman ini admin dapat melakukan perubahan status invoice dari unpaid manjadi paid (terbayar), delivered (terkirim) atau canceled (dibatalkan). Pada halaman ini dapat dilakukan pencarian terhadap invoice dandetailproduknya 


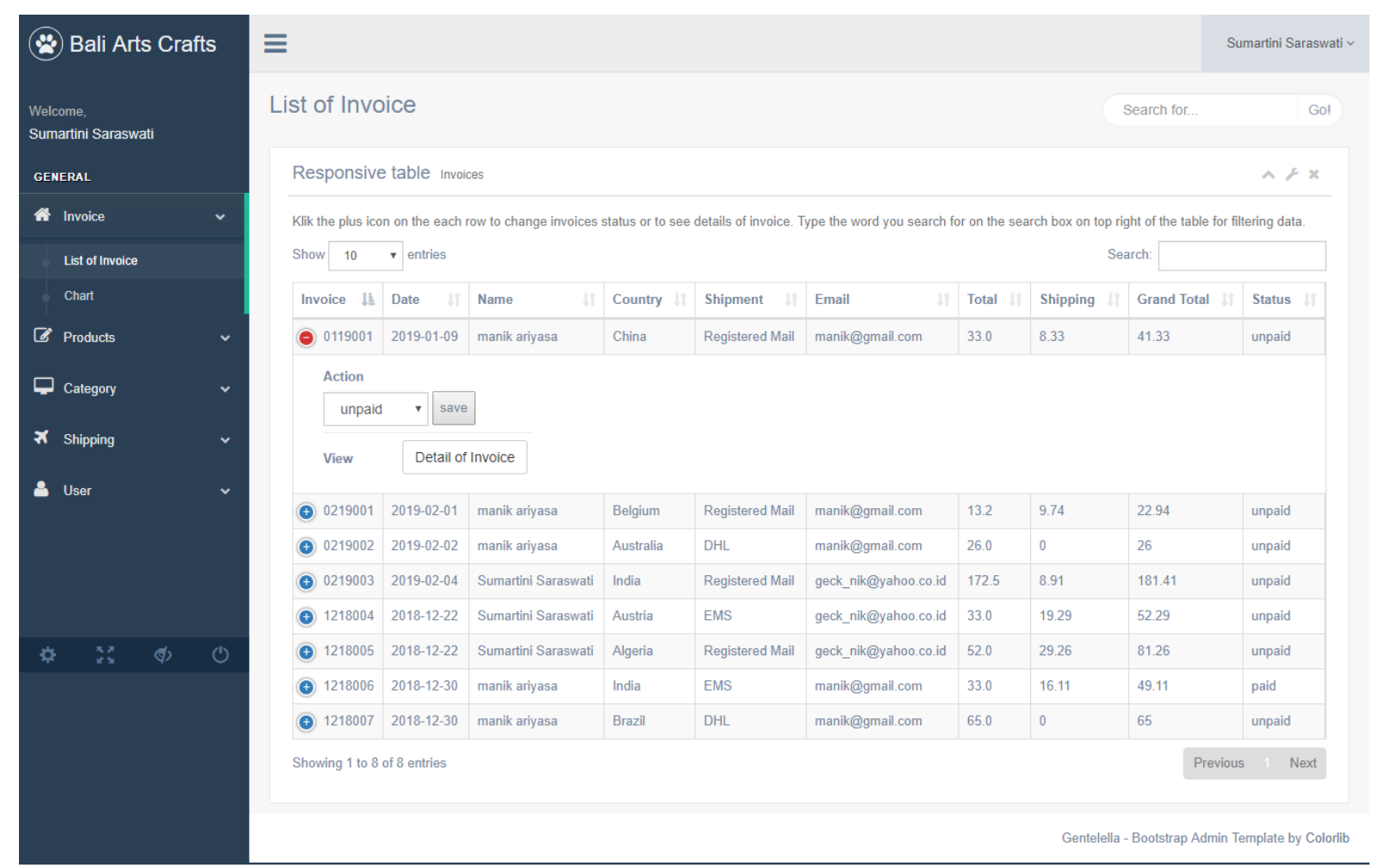

Gambar 11. Halaman List Invoice

\section{Halaman list produk}

Pada halaman ini terdapat daftar produk yang ditawarkan dalam website penjualan. Untuk tiap produk dapat dilakukan proses edit maupun delete. Proses delete dilindungi oleh integrity constraint yang diatur dalam DBMS. 


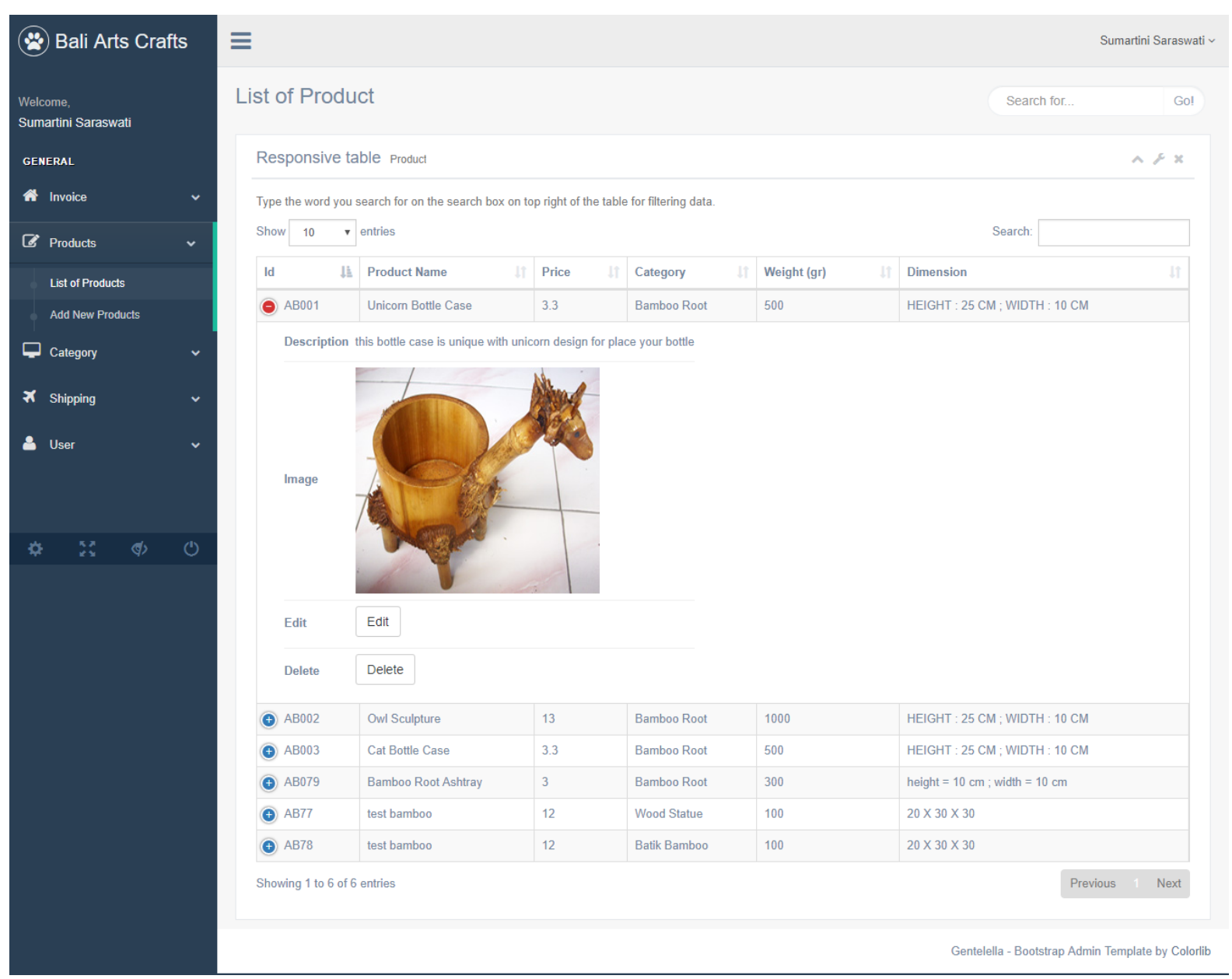

Gambar 12. Halaman List Produk

\section{SIMPULAN}

User dalam sistem ini terbagi menjadi konsumen dan admin, demikian juga untuk pembagian halaman website. Untuk spesifikasi minimum tabel yang diperlukan adalah tabel invoice, detail invoice, user, produk, kategori, shipping. Proses pembelian produk diawali dengan pemilihan barang kemudian shopping cart dan diakhiri dengan proses check out. Manajemen data master dilakukan pada halaman admin dengan proses autentikasi untuk mengaksesnya.

Pada penelitian ini perancangan dan pengembangan website e-commerce dilakukan dalam ruang lingkup spesifikasi minimum. Dalam pengembangan berikutnya dapat ditambahkan fitur-fitur fungsional yang dapat menambah kehandalan sistem.

\section{DAFTAR PUSTAKA}

[1] Anonym, http://www.bekraf.go.id/profil. [Diunduh pada tanggal 16 Juni 2018].

[2] Anonym, https://www.merdeka.com/uang/eksporbambu-indonesia-menempati-peringkat-tigadunia.html. [Diunduh pada tanggal 16 Juni 2018.]

[3] A,O'Brien, James. (2003). Introduction to Information System Essential for $E$ Business Enterprise Eleventh Edition. New York : McGraw-Hill.

[4] McLeod, R. dan Schell, G.P.(2001). Aplikasi Pengolahan. Jakarta : Penerbit Prenhallindo.

[5] Nugroho, A. 2006. E-Commerce Memahami Perdagangan Modern di Dunia Maya. Bandung: Informatika

[6] Purbo, W.O. dan Wahyudi, A.A. 2001. Mengenal E-Commerce. Jakarta: Alex Komputindo 
[7] Quthni, D. (n.d.). Pengertian Electronic Commerce (E-Commerce),

URL:http://darul-

ecom.piksiinputserang.ac.id/

[8] Suyanto. 2006. Dasar-dasar Perancangan

Web Dari Pemula Sampai Mahir. Jakarta:

PT. Elex Media Komputindo. 